\title{
Generation of the additional fluorescence radiation in the elastomeric shields used in computer tomography (CT)
}

\author{
P. Szajerski $\cdot$ M. Zaborski $\cdot$ H. Bem • \\ W. Baryn · E. Kusiak
}

Received: 29 April 2013/Published online: 31 May 2013

(C) The Author(s) 2013. This article is published with open access at Springerlink.com

\begin{abstract}
Two commercially available (EP, Z) and eight new elastomeric composites (M1-M4, G1-G4, of thickness $\approx 1 \mathrm{~mm}$ ) containing mixtures of differing proportions of heavy metal additives ( $\mathrm{Bi}, \mathrm{W}, \mathrm{Gd}$ and $\mathrm{Sb}$ ) have been synthesised and examined as protective shields. The intensity of the $\mathrm{X}$-ray fluorescence radiation generated in the typical elastomeric shields for CT, containing Bi and other heavy metal additives influence on the practical shielding properties. A method for assessing the radiation shielding properties of elastomeric composites used in CT examination procedures via X-ray spectrometry has been proposed. To measure the radiation reduction ability of the protective shields, the dose reduction factor (DRF) has been determined. The lead equivalents for the examined composites were within the ranges of $0.046-0.128$ and $0.048-0.130 \mathrm{~mm}$ for 122.1 and $136.5 \mathrm{keV}$ photons, respectively. The proposed method, unlike to the common approach, includes a dose contribution from the induced $\mathrm{X}$-ray fluorescence radiation of the heavy metal elements in the protective shields. The results clearly indicate that among the examined compositions, the highest values DRF have been achieved with preparations containing $\mathrm{Bi}+\mathrm{W}$, $\mathrm{Bi}+\mathrm{W}+\mathrm{Gd}$ and $\mathrm{Bi}+\mathrm{W}+\mathrm{Sb}$ mixtures with gradually decreasing content of heavy metal additives in the following order: $\mathrm{Bi}, \mathrm{W}, \mathrm{Gd}$ and $\mathrm{Sb}$. The respective values of DRF obtained for the investigated composites were 21,28
\end{abstract}

P. Szajerski $(\bowtie) \cdot$ H. Bem

Institute of Applied Radiation Chemistry, Lodz University of Technology, Wroblewskiego 15, 90-924 Lodz, Poland e-mail: piotr.szajerski@p.lodz.pl; szajer@mitr.p.lodz.pl

M. Zaborski · W. Baryn · E. Kusiak Institute of Polymer and Dye Technology, Lodz University of Technology, Stefanowskiego 12/16, 90-924 Lodz, Poland and $27 \%$ dose reduction for a $1 \mathrm{~mm}$ thick shield and 39 and $\sim 50 \%$ for a $2 \mathrm{~mm}$ thick layer (M1-M4).

Keywords X-ray florescence radiation - Dose reduction . Shielding composites $\cdot$ Heavy metal additives $\cdot$ CT elastomer shields

\section{Introduction}

Computed tomography (CT) is valuable diagnostic tool widely used in medical practices. Unfortunately, this technique employs use of X-ray radiation resulting in relatively high average effective doses from $2.4 \mathrm{mSv}$ (head examination) up to $12.4 \mathrm{mSv}$ (abdomen), usually exceeding the average yearly doses from natural radiation of $2.4 \mathrm{mSv}$ [1]. Because of the powerful diagnostic possibilities with $\mathrm{CT}$ and its clinical benefits, the use of CT has increased explosively. For example, in the UK the use of CT has grown in the last decade from accounting for $5-11 \%$ of all X-ray examinations to contributing up to $68 \%$ of the collective radiation doses from these sources [2]. According to the 2008 UNSCEAR report, 221 million CT examinations are performed annually worldwide [1] with over 70 million in US alone in 2007 [4]. Moreover, a rapid increase in paediatric CT has been observed, and because children experience higher lifetime risks of fatal cancer with each dose, one can expect an increased incidence in some types of cancers attributable to CT among this group. Despite many reports concerning the estimated cancer risk from CT [3, 4], particularly from paediatric CT [5], the problem of the dose reduction during $\mathrm{CT}$ scans has frequently been underestimated [6]. This problem has been additionally exacerbated by questioning the validity of the linear, no-threshold model (LNT) for the relationship 
between an effective dose and increased cancer risks for doses below $100 \mathrm{mSv}$ [7, 8]. However, recent statistically based epidemiological studies have proven a long-term link between early childhood exposure for treatment of an enlarged thymus (low-dose chest therapy) with an increase in the relative risk of thyroid cancers in patients as compared with their non-irradiated siblings [9]. Similarly, a recent report concerning a large study of over 176,000 patients examined using CT in the National Health Service centres in the UK demonstrated a positive association between the radiation dose from CT scans and leukaemia and brain tumours [10]. These findings confirmed the necessity of developing new guidelines for CT scans to reduce the doses of radiation received during these examinations.

Designing new CT machines with reduced radiation exposure with improvement in the CT techniques could offer the ability to scan a chosen portion of the patient using low-tube voltage protocols to substantially decrease the doses [11].

An alternative method for dose reduction during CT examination involves the use of plastic composites with metal additives as a shield, particularly for radiosensitive organs such as the eyes, thyroid glands, breast or gonads. Such planar shields containing bismuth compounds are currently used in radiology as they are commercially available, and their practical use has recently been reviewed [6]. However, the use of these shields is recommended on the basis of dose reduction determined at positions chosen using human-tissue-equivalent anthropomorphic phantoms $[12,13]$. Application of heavy metal additives is crucial due to their strong X-ray radiation attenuation capabilities. However, one must keep in mind that excitation of heavy metal atoms after absorption of the incoming X-ray radiation may result in the generation of secondary X-ray fluorescence radiation, which can escape the shields and diminish their absorption effect. This effect can cause the artifactually increase CT of numbers and adversely affect the accuracy of CT numbers as well as may also influence the image quality of the CT scan [14]. The other disadvantages, associated with the use of bismuth shields, especially when used with automatic exposure control or tube current modulation. may lead to unpredictable and potentially undesirable levels of dose. Therefore, AAPM [15] and the Society of Cardiac CT stated, that these shields are not recommended for CT scanning [16]. However, such attitude is also discussed, as the use of bismuth shields has unquestionable advantages, especially in paediatric CT and some of these disadvantages can be simply reduced $[17,18]$.

A simple way to improve the quality of CT scans with simultaneous reducing of the doses with bismuth shield is reducing of the dispersed by these shields radiation.

The principal idea of this study was to evaluate the contribution of secondary excited $\mathrm{X}$-ray fluorescence in $\mathrm{Bi}$ containing shields and to examine the possibility of reducing its intensity via the simultaneous application of a few metal additives to absorb X-ray photons of sequentially higher excitation energies and shift them to lower energy bands that are much easier to attenuate and do not impact either the total dose absorbed during or the diagnostic quality of the CT scans.

\section{Materials and methods}

Eight different elastomeric shields containing Bi, W, Gd and $\mathrm{Sb}$ in various proportions have been prepared to determine the dose reduction factor (DRF) and their suitability as shields in CT examination procedures.

The elastomeric samples have been prepared by pressing natural rubber with typical vulcanisation additives and with heavy metal admixtures in the form of the following oxides: $\mathrm{Bi}_{2} \mathrm{O}_{3}, \mathrm{WO}_{3}, \mathrm{Gd}_{2} \mathrm{O}_{3}$ and $\mathrm{Sb}_{2} \mathrm{O}_{3}$. The final vulcanisation has been carried out at $160{ }^{\circ} \mathrm{C}$. The rubber compounds with their formulations are provided in Table 1.

Table 1 Composition of elastomer mixtures

\begin{tabular}{|c|c|c|c|c|c|c|c|c|c|}
\hline $\begin{array}{l}\text { Sample } \\
\text { code }\end{array}$ & $\begin{array}{l}\text { NR } \\
(\mathrm{g})\end{array}$ & $\begin{array}{l}\mathrm{ZnO} \\
(\mathrm{phr})\end{array}$ & $\begin{array}{l}\text { Sulphur } \\
\text { (phr) }\end{array}$ & $\begin{array}{l}\text { MBT } \\
(\mathrm{phr})\end{array}$ & $\begin{array}{l}\text { Stearic acid } \\
\text { (phr) }\end{array}$ & $\begin{array}{l}\mathrm{Bi}\left(\mathrm{Bi}_{2} \mathrm{O}_{3}\right) \\
\text { (phr) }\end{array}$ & $\begin{array}{l}\mathrm{W}\left(\mathrm{WO}_{3}\right) \\
(\mathrm{phr})\end{array}$ & $\begin{array}{l}\mathrm{Gd}\left(\mathrm{Gd}_{2} \mathrm{O}_{3}\right) \\
(\mathrm{phr})\end{array}$ & $\begin{array}{l}\mathrm{Sb}\left(\mathrm{Sb}_{2} \mathrm{O}_{3}\right. \\
(\mathrm{phr})\end{array}$ \\
\hline M1 & 100 & 5 & 2 & 2 & 1 & $100(111.5)$ & - & - & - \\
\hline M2 & 100 & 5 & 2 & 2 & 1 & 100 (111.5) & $50(63)$ & - & - \\
\hline M3 & 100 & 5 & 2 & 2 & 1 & 100 (111.5) & $50(63)$ & $25(28.8)$ & - \\
\hline M4 & 100 & 5 & 2 & 2 & 1 & 100 (111.5) & $50(63)$ & $25(28.8)$ & $10(12)$ \\
\hline G1 & 100 & 5 & 2 & 2 & 1 & $50(55.75)$ & - & - & - \\
\hline G2 & 100 & 5 & 2 & 2 & 1 & $50(55.75)$ & $50(63)$ & - & - \\
\hline G3 & 100 & 5 & 2 & 2 & 1 & $50(55.75)$ & $50(63)$ & $50(57.6)$ & - \\
\hline G4 & 100 & 5 & 2 & 2 & 1 & $50(55.75)$ & $50(63)$ & $50(57.6)$ & $50(60)$ \\
\hline
\end{tabular}

phr parts per hundred rubber, $n r$ natural rubber, $M B T$ 2-Mercaptobenzothiazole 
Using this procedure, radiopaque composite elastomers in the form of planar shields $\left(25 \times 25 \mathrm{~cm}^{2}\right)$ with a thickness of $1 \mathrm{~mm}$ were obtained as a starting material for the protective shields [19]. The lead equivalent of these natural rubber vulcanisates was $0.04-0.16 \mathrm{~mm}$ at $60 \mathrm{keV} \mathrm{X}$-ray radiation. The detailed compositions of the examined shields are presented in Table 2, with samples of equal metallic additive content (G1-G4) and with heavy metal content that decreases progressively in the following order: $\mathrm{Bi}, \mathrm{W}, \mathrm{Gd}$ and $\mathrm{Sb}$ (samples M1-M4). To study new compositions, two commercially available shields have been examined (SOMATEX ${ }^{\circledR}$ CT Shields, samples EP and Z, SOMATEX MEDICAL TECHNOLOGIES GMBH, Germany).

For a radiation source that mimics the X-ray tube radiation used in CT, a Co-57 closed isotopic source has been applied providing $\gamma$-rays of $122.1(85.6 \%)$ and 136.5 (10.7\%) keV., which closely approximates the typical $\mathrm{X}$-ray tube voltages applied in CT examinations. The intensity of the excited X-ray photons was measured using a $\gamma$-ray spectrometry system with a high-resolution REGe detector placed in a $5 \mathrm{~cm}$ thick lead shielding housing lined with a $5 \mathrm{~mm}$ thick $\mathrm{Zn}$ plate cylinder. The resolution of the detector was $0.9 \mathrm{keV}$ for the $122 \mathrm{keV}$ peak, and its relative efficiency was $20 \%$ for the $1.33 \mathrm{MeV}$ peak. The data were processed using a model S404 Inspector Spectroscopy System (Canberra). Details of the detection system are described elsewhere [20]. A schematic diagram of the measuring system is shown in Fig. 1.

The Co-57 radionuclide was commercially available and sealed in a polycarbonate case. To minimize the excitation of the atoms from the lead shield and the possible interference of their radiation with the detector, the Co-57 source was also placed in a brass shielding housing. Two brass collimators were used to diminish the influence of scattered radiation. All spectra were recorded using Genie 2000 software from Canberra over 1,800 s. Each elastomeric shield sample had dimensions of approximately $4 \times 4 \mathrm{~cm}^{2}$. The active area of the sample, visible to the detector, was a $12.3 \mathrm{~mm}$ diameter surface $\left(\sim 120 \mathrm{~mm}^{2}\right)$.

Table 2 Elemental composition of the examined shields

\begin{tabular}{|c|c|c|c|c|c|c|c|c|c|c|c|c|c|}
\hline \multirow{2}{*}{$\begin{array}{l}\text { Sample } \\
\text { code }\end{array}$} & \multirow{2}{*}{$\begin{array}{l}\text { Thickness } \\
(\mathrm{cm})\end{array}$} & \multirow{2}{*}{$\begin{array}{l}\text { Thickness } \\
\left(\mathrm{g} / \mathrm{cm}^{2}\right)\end{array}$} & \multirow{2}{*}{$\begin{array}{l}\text { Density } \\
\left(\mathrm{g} / \mathrm{cm}^{3}\right)\end{array}$} & \multicolumn{10}{|c|}{ Mass fraction } \\
\hline & & & & $\mathrm{H}$ & $\mathrm{C}$ & $\mathrm{N}$ & $\mathrm{O}$ & S & $\mathrm{Zn}$ & $\mathrm{Sb}$ & $\mathrm{Gd}$ & W & $\mathrm{Bi}$ \\
\hline M1 & 0.116 & 0.195 & 1.685 & 0.0543 & 0.4060 & 0.0008 & 0.0568 & 0.0125 & 0.0181 & & & & 0.4515 \\
\hline M2 & 0.120 & 0.244 & 2.032 & 0.0423 & 0.3161 & 0.0006 & 0.0900 & 0.0097 & 0.0141 & & & 0.1756 & 0.3515 \\
\hline M3 & 0.105 & 0.230 & 2.190 & 0.0384 & 0.2871 & 0.0005 & 0.0939 & 0.0088 & 0.0128 & & 0.0798 & 0.1595 & 0.3192 \\
\hline M4 & 0.108 & 0.236 & 2.185 & 0.0370 & 0.2765 & 0.0005 & 0.0965 & 0.0085 & 0.0123 & 0.0308 & 0.0768 & 0.1536 & 0.3075 \\
\hline G1 & 0.098 & 0.134 & 1.363 & 0.0725 & 0.5426 & 0.0010 & 0.0412 & 0.0167 & 0.0242 & & & & 0.3017 \\
\hline $\mathrm{G} 2$ & 1.000 & 0.178 & 0.178 & 0.0525 & 0.3931 & 0.0007 & 0.0869 & 0.0121 & 0.0176 & & & 0.2185 & 0.2185 \\
\hline G3 & 0.093 & 0.176 & 1.894 & 0.0420 & 0.3140 & 0.0006 & 0.0961 & 0.0097 & 0.0140 & & 0.1746 & 0.1746 & 0.1746 \\
\hline G4 & 0.095 & 0.174 & 1.836 & 0.0347 & 0.2597 & 0.0005 & 0.1079 & 0.0080 & 0.0116 & 0.1444 & 0.1444 & 0.1444 & 0.1444 \\
\hline EP & 0.043 & 0.162 & 3.789 & na & na & na & na & na & na & na & + & + & + \\
\hline $\mathrm{Z}$ & 0.103 & 0.172 & 1.668 & na & na & na & na & na & na & na & - & - & + \\
\hline
\end{tabular}

"+" or "-" presence detected or not detected

na data not available

Fig. 1 Schematic diagram of the experimental setup

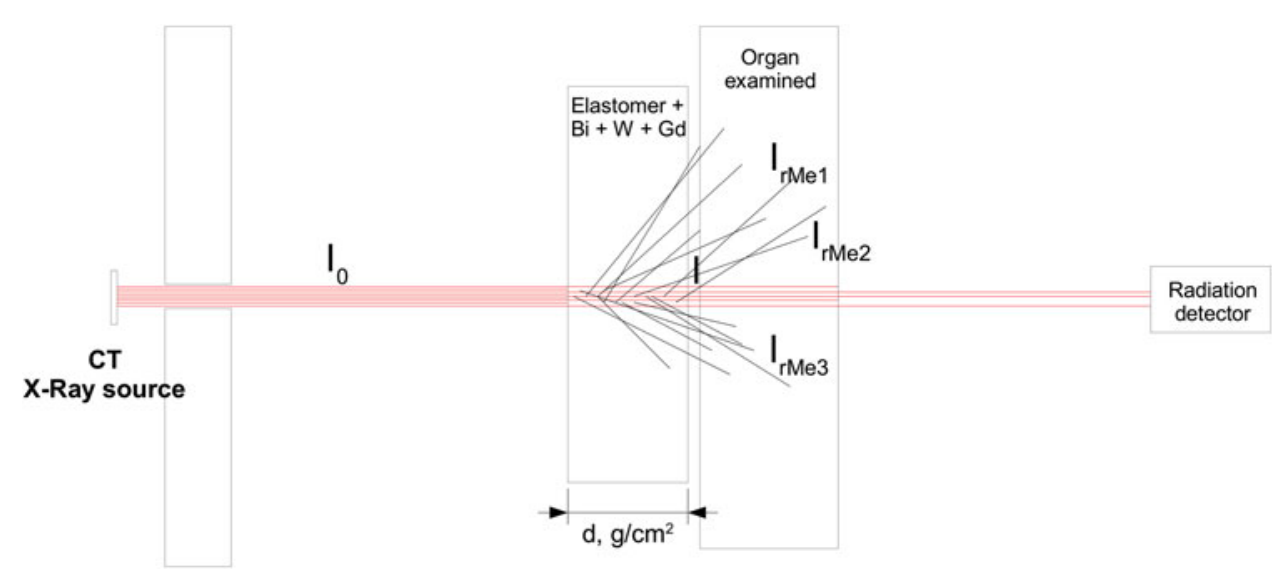


The mass attenuation coefficients for the two main Co-57 emission lines (122.1 and $136.5 \mathrm{keV}$ ) were determined according to the well-known exponential dependence:

$I=I_{0} e^{-\mu x}$

in which $\mu$ is the mass attenuation coefficient in $\mathrm{cm}^{2} / \mathrm{g}$ and $x$ is the thickness in $\mathrm{g} / \mathrm{cm}^{2}$. The given formula meets all experimental conditions for a narrow monoenergetic photon beam; otherwise, a build-up factor (B) should be introduced. In our experiments no build-up factor was required for Eq. 1, as confirmed during the validation experiments.

Because many naturally occurring radionuclides contribute to the background radiation in the $\gamma$ - and X-ray spectra within the energy range of interest (from 40 to $100 \mathrm{keV}$ measured over $60,000 \mathrm{~s}$ ), their contribution to the natural detector background was subtracted from each recorded spectrum. In addition, to achieve better accuracy and more reliable results, a correction for the Compton continuum was performed.

Calculations of the theoretical mass attenuation coefficients based on the sample compositions were performed using XCom software available from the National Institute of Standards and Technology (NIST) website [21, 22]. The composition data for the human tissue (soft) used $(\mathrm{H}$ $10.20 \%$, C $14.30 \%$, N $3.40 \%$, O $70.80 \%$, Na $0.20 \%$, P $0.30 \%, \mathrm{~S} 0.30 \%, \mathrm{Cl} 0.20 \%, \mathrm{~K} 0.30 \%$ ) to calculate the mass attenuation coefficient and dose reduction factor were also taken from the NIST database [23] and based on the data included in the ICRU 44 report [24].

\section{Results and discussion}

The experimental procedure required validation of the experimental setup and methods used for the calculations. Simple measurements of the standardised $\mathrm{Pb}$ plates were carried out for this validation during which the mass attenuation coefficients were determined for the lead. The results obtained were in good agreement with the theoretical values, and the relative error of this method was approximately $1 \%$. These values confirm that this methodology can be successfully applied for mass attenuation coefficient measurements in samples of novel composition whose physical properties have not been fully determined. The application of a Co-57 radiation source only allows for experimental determination of mass attenuations coefficients for 122.1 and $136.5 \mathrm{keV}$ photons. The measured values of the attenuation coefficients for the Co-57 $\gamma$ lines at 122.1 and $136.5 \mathrm{keV}$ are in good agreement with the values calculated taking into account the elastomer compositions. The relative deviation between the measured values and those calculated does not exceed $15 \%$. The lower energy mass attenuation coefficients used to calculate the dose reduction factor were determined via calculations based on a particular sample composition. Table 3 presents the calculated and measured values for the $\mu$ coefficients and the equivalent lead values for the investigated shields at both 122.1 and $136.5 \mathrm{keV}$.

The X-ray excitation spectra for the four rubber shields containing $\mathrm{Bi}$ at practically the same concentration as the other metal additives (0.30-0.35 mass fraction), $\mathrm{Bi}+\mathrm{W}$ (0.176 W mass), $\mathrm{Bi}+\mathrm{W}+\mathrm{Gd}(0.160$ and 0.080 mass fractions of $\mathrm{W}$ and $\mathrm{Gd}$, respectively) and $\mathrm{Bi}+\mathrm{W}+\mathrm{Gd}+\mathrm{Sb}$ (0.154, 0.077 and 0.031 mass fractions of $\mathrm{W}, \mathrm{Gd}$ and $\mathrm{Sb}$, respectively) are presented in Fig. 2. As shown in the figure, the X-ray photon intensities of 74.8, 77.1, 87.3 and $89.9 \mathrm{keV}$ are observed for shield containing Bi only [25]. Additionally two energy lines that do not originate from $\mathrm{Bi}$ excitation, 72.8 and $84.7 \mathrm{keV}$ [25], are also observed and should be assigned to $\mathrm{Pb}$ excitation, which is present despite strong shielding by the detector housing. A natural explanation for this fact is that lead housing excitation can arise from cosmic radiation as confirmed during the background measurements and the partial excitation of lead via the Co-57 $\gamma$ photons, which although strong attenuated, were not fully absorbed by the shield. After analysis of the recorded spectra, one can conclude, that although much weaker than the photon intensity of the Co-57 source, the secondary X-ray fluorescence radiation arising from the protective shield, should be considered as a dose contributor to the irradiated tissue. The dose aspect and the quality of the registered CT scans suffer because of the additional induced X-ray fluorescence radiation. The addition of a second metallic component with a lower atomic number $\mathrm{Z}$ could absorb the Bi X-ray fluorescence photons. For this purpose, the addition of tungsten was examined. The

Table 3 Attenuation coefficients for 122.1 and $136.5 \mathrm{keV}$ photons and calculated lead equivalents values for investigated elastomeric composites

\begin{tabular}{llllll}
\hline Elastomer & $\begin{array}{l}d(1 \text { layer }) \\
\left(\mathrm{g} / \mathrm{cm}^{2}\right)\end{array}$ & $\begin{array}{l}\mu_{122.1} \\
\left(\mathrm{~cm}^{2} / \mathrm{g}\right)\end{array}$ & $\begin{array}{l}R_{\mathrm{Pb}-122.1} \\
(\mathrm{~mm})\end{array}$ & $\begin{array}{l}\mu_{136.5} \\
\left(\mathrm{~cm}^{2} / \mathrm{g}\right)\end{array}$ & $\begin{array}{l}R_{\mathrm{Pb}-136.5} \\
(\mathrm{~mm})\end{array}$ \\
\hline $\mathrm{M} 1$ & 0.195 & 1.659 & 0.085 & 1.274 & 0.086 \\
$\mathrm{M} 2$ & 0.244 & 1.768 & 0.128 & 1.352 & 0.130 \\
M3 & 0.230 & 1.755 & 0.120 & 1.340 & 0.121 \\
$\mathrm{M} 4$ & 0.236 & 1.724 & 0.121 & 1.316 & 0.122 \\
$\mathrm{G} 1$ & 0.134 & 1.164 & 0.046 & 0.905 & 0.048 \\
$\mathrm{G} 2$ & 0.178 & 1.435 & 0.076 & 1.102 & 0.077 \\
$\mathrm{G} 3$ & 0.176 & 1.474 & 0.077 & 1.127 & 0.078 \\
$\mathrm{G} 4$ & 0.174 & 1.375 & 0.071 & 1.052 & 0.072 \\
$\mathrm{EP}$ & 0.162 & 1.606 & 0.068 & 1.206 & 0.068 \\
$\mathrm{Z}$ & 0.172 & 1.555 & 0.080 & 1.174 & 0.079 \\
\hline
\end{tabular}


presence of tungsten in the elastomeric bismuth shield leads to a substantial reduction of the all $\mathrm{Bi}$ line intensities as evidenced by the presented spectra. However, as a result, four new $\mathrm{W}$ photon emission lines are generated in the lower portion of the spectrum with energies characteristic of $\mathrm{W}$ excitation, 58.0, 59.3, 67.2 and $69.1 \mathrm{keV}$ (M2 composite) [25]. These photons can be absorbed by the addition of another additive with a lower $\mathrm{Z}$ and $\mathrm{X}$-ray excitation levels slightly below the energy of tungsten-emitted photons, for example, gadolinium. The addition of this element results in a reduction in the $\mathrm{W}$ emission intensity; however, two group of photons of 42.7 and $48.7 \mathrm{keV}$ energy, corresponding to gadolinium emissions (M3) [25], are generated with lower intensities. These photons can be absorbed more easily than those emitted by $\mathrm{Bi}$ or $\mathrm{W}$ with energies of approximately 60-90 keV. A similar effect of reduced Gd $\mathrm{X}$-ray emission photons could be expected after the addition of Sb (composite M4); however, as shown in Fig. 2, this result is not clear. From the other side, the low-energy Gd X-ray emission is not as important as the Bi and $\mathrm{W}$ fluorescence radiation emission together with the 120-140 keV Co-57 $\gamma$ radiation. More detailed observations can be seen in Figs. 3 and 4 in which the data collected for particular photon emission intensities for $\mathrm{Bi}, \mathrm{W}$ and Gd are presented for each composite. Given that the lower limit of photon energy visible to our REGe detector is $\sim 40 \mathrm{keV}$, no $\gamma$-ray or X-ray photons below this value were observed, which is of concern to the $\mathrm{Sb}$ emission. This fact renders the measurement of photon emissions below $40 \mathrm{keV}$ for $\mathrm{Bi}, \mathrm{W}$ and $\mathrm{Gd}$ impossible. However, due to strong absorption of photons from this energy range and the reduced fluorescence yields for the excitation from shells other than $\mathrm{K}$, the contributions photons at energies below $40 \mathrm{keV}$ could, in practice, be neglected from the total doses outside the shields.

The intensity of the X-ray fluorescence radiation generated by the interaction of the photons with matter depends on the many factors [26]. This interaction is governed by the following variables: interacting photon flux $\left(R_{\gamma}\right)$, the probability of the photoelectric absorption $(\tau)$, the photon emission probability or fluorescence yield $(\omega)$ for a particular absorption process (K, L1, L2, L3, etc.), the branching ratio for a specific transition of electron de-excitation process (KL2, KL3, KM2, etc.), the concentration of the element being excited $\left(c_{\mathrm{Me}}\right)$ and finally, the thickness of the irradiated material $(x)$. Additionally, X-ray excitation radiation will be absorbed within the material $\left(\mu_{\mathrm{f}}\right)$. In general, when more than one group of photons can interact with the irradiated material, the intensity $R_{\mathrm{f}}$ (photons/s) of the characteristic X-rays generated at distance $\mathrm{dx}$ within the shield by the $\gamma$ ray excitation source is given by Eq. 2 .

$\mathrm{d} R_{\mathrm{F}}=\omega B c_{\mathrm{Me}}\left(\sum_{i} R_{\gamma i} \tau_{i}\right) \mathrm{d} x-R_{\mathrm{f}} \mu_{\mathrm{f}} \mathrm{d} x$

In our experiments, the Co-57 source emits two $\gamma$ photons at slightly distinct energies. Thus, Eq. 2 will be transformed to Eq. 3.

$$
\mathrm{d} R_{\mathrm{F}}=\omega B c_{\mathrm{Me}}\left(R_{\gamma 1}^{0} e^{-\mu_{1} x} \tau_{1}+R_{\gamma 2}^{0} e^{-\mu_{2} x} \tau_{2}\right) \mathrm{d} x-R_{\mathrm{f}} \mu_{\mathrm{f}} \mathrm{d} x
$$

Fig. 2 Influence of metallic additives $\left(x_{\mathrm{Me}}\right)$ on X-ray emission spectra of the elastomeric shields

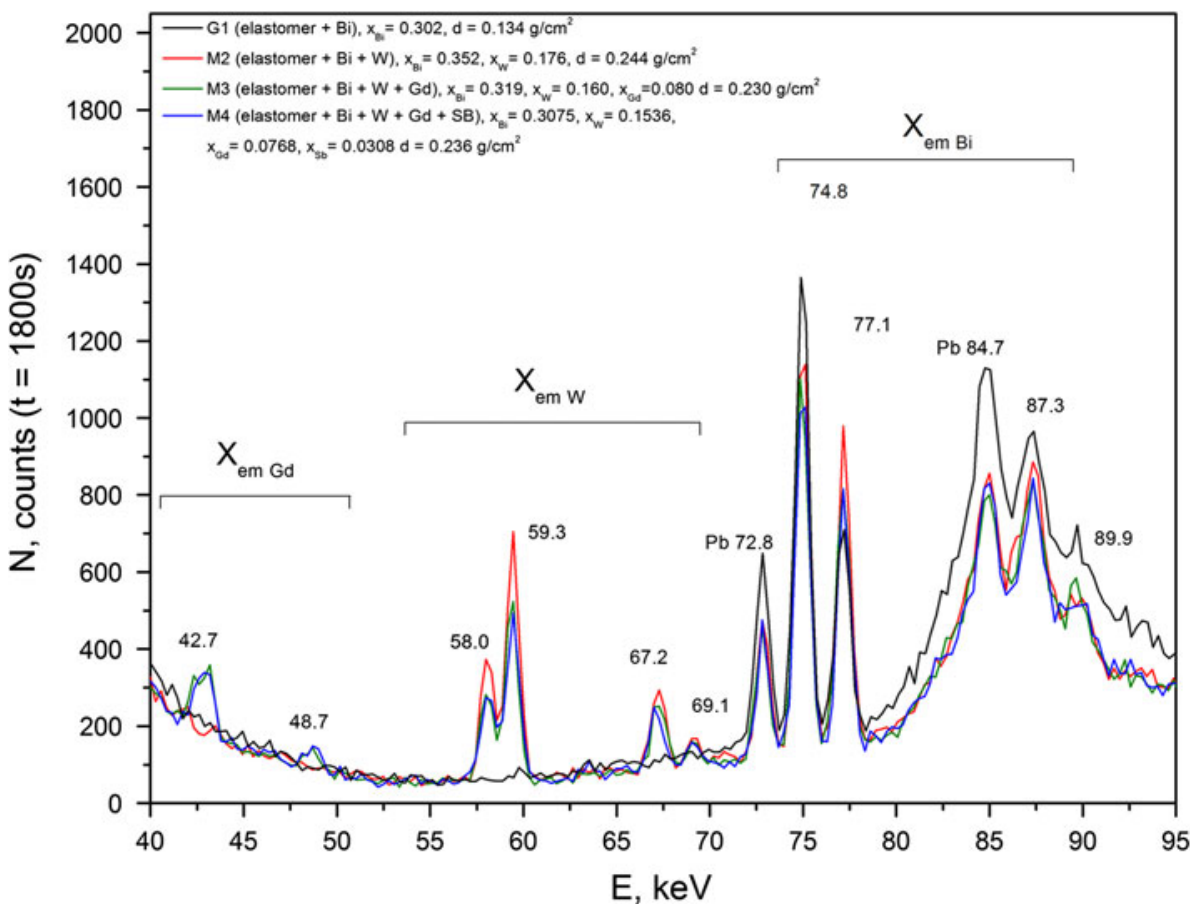



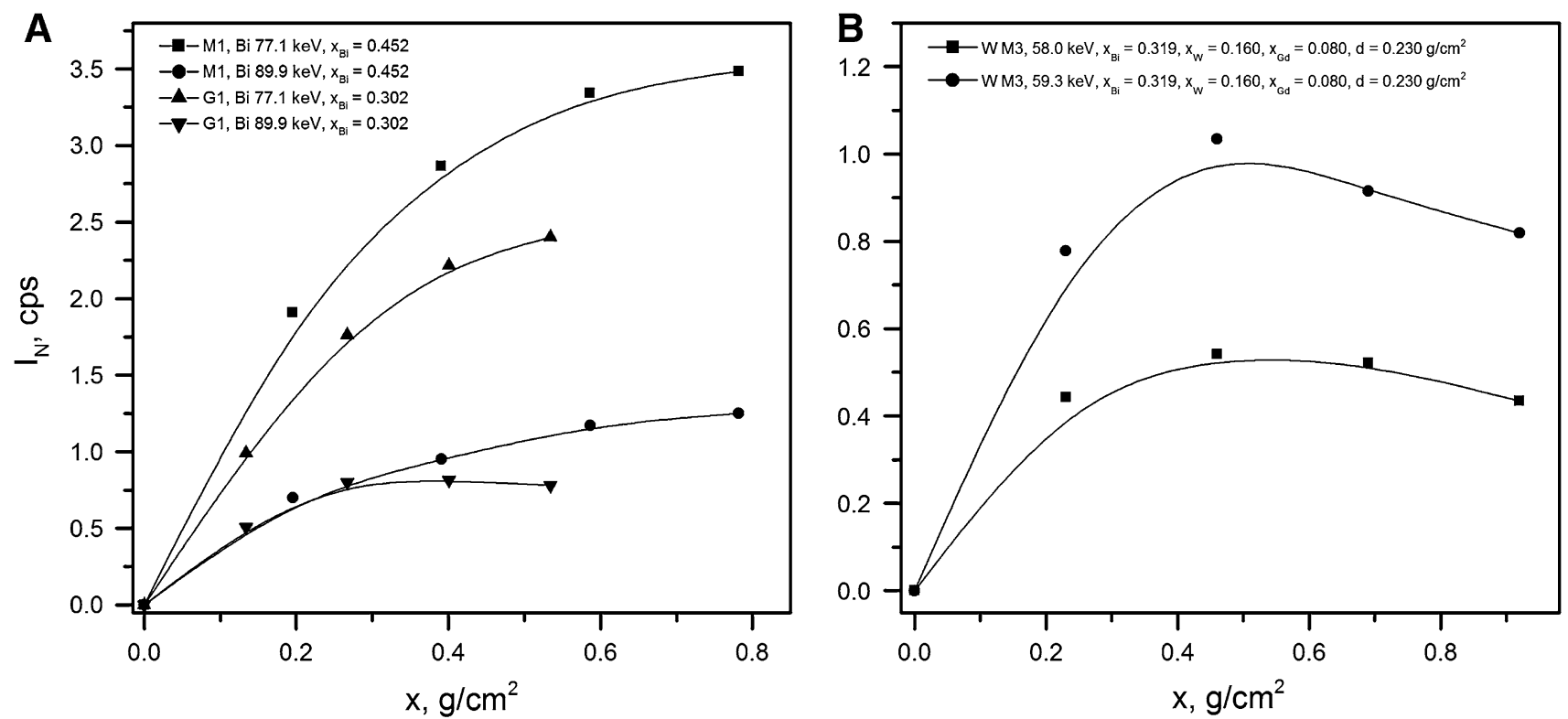

Fig. 3 (a) Influence of the shield thickness on the intensities of the two different Bi concentrations (89.9 and $77.1 \mathrm{keV}$ lines); (b) Effect of the shield thickness on the intensity of two $\mathrm{W}$ emission lines (for 58.0 and $59.3 \mathrm{keV}$ photons) for composites containing Gd
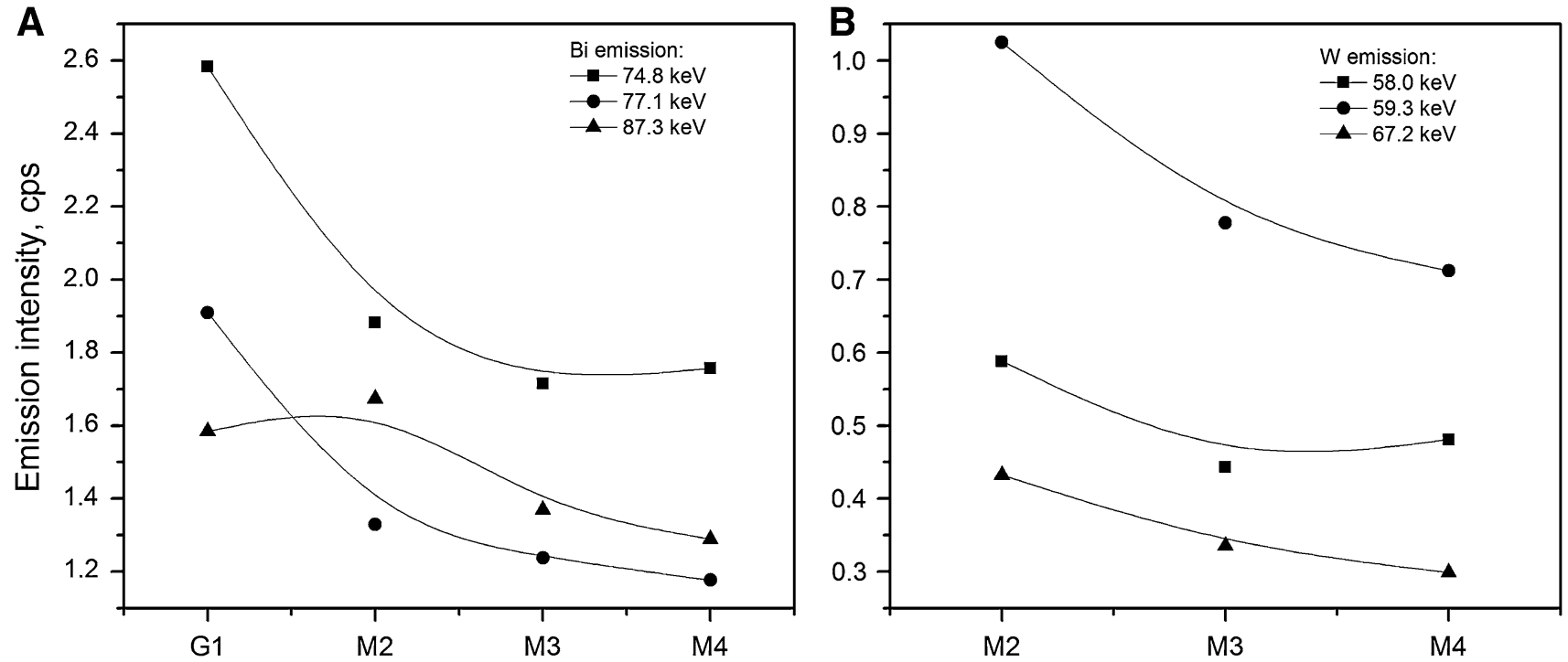

Fig. 4 Comparison of the main X-ray emission lines intensities of Bi (a), and W (b) for chosen composite shields

in which $R_{\gamma 1}^{0}$ and $R_{\gamma 2}^{0}$ equal the initial intensities of the excitation photons from the Co-57 source at 122.1 and $136.5 \mathrm{keV}$, respectively; $\tau_{1}$ and $\tau_{2}$ represent the photoelectric absorption coefficients for a given photon energy and metal additive; $\mu_{1}, \mu_{2}$ and $\mu_{\mathrm{f}}$ are the mass attenuation coefficients for 122.1, $136.5 \mathrm{keV}$ and the secondary fluorescence radiation, respectively, in $\mathrm{cm}^{2} / \mathrm{g} ; \omega$ and $B$ represent the $\mathrm{K}$ fluorescence yield and branching ratio for the transition of a specific X-ray emission photon energy; $c_{\mathrm{Me}}$ is the concentration of the metal additive in the bulk material; and $\mathrm{d} x$ represents the shield surface density increment in $\mathrm{g} / \mathrm{cm}^{2}$.
After integrating Eq. 3 for the initial condition of $R_{\mathrm{f}}=0$ for $x=0$, one can obtain the following solution for the intensity $R_{\mathrm{f}}$ of any particular characteristic X-ray photon generated in a shield of thickness $x$ (eq. 4):

$$
\begin{aligned}
R_{\mathrm{f}}= & \frac{R_{\gamma 1}^{0} \tau_{1} \omega B c_{\mathrm{Me}}}{\mu_{\mathrm{f}}-\mu_{1}}\left(e^{-\mu_{1} x}-e^{-\mu_{\mathrm{f}} x}\right) \\
& +\frac{R_{\gamma 2}^{0} \tau_{2} \omega B c_{\mathrm{Me}}}{\mu_{\mathrm{f}}-\mu_{2}}\left(e^{-\mu_{2} x}-e^{-\mu_{\mathrm{f}} x}\right)
\end{aligned}
$$

Under these experimental conditions, the observed intensity in the fluorescence radiation is primarily dependent 
on the first segment of this two-component relationship, while the second component only partially contributes to the total $\mathrm{X}$-ray photon intensity. This conclusion can be easily justified by the contribution of the $136.5 \mathrm{keV}$ radiation flux as compared with that of the main line, which is $122.1 \mathrm{keV}$ (10.7\% emission probability towards $85.6 \%$ ). The attenuation factor for the higher energy photons is slightly reduced in the given material, which in fact increases the second component, and does not essentially affect this proportion. This relationship can lead to a saturation curve or a curve with a maximum of fluorescent radiation intensity whose position depends on the physical parameters of the system, particularly the attenuation coefficients. Obviously, these attenuation coefficients, $\mu$, are strongly dependent on the effective atomic number of the shield [27], as is the function of the heavy metal content. In contrast, an increase in the concentration of heavy metals results in a higher probability of photon-Bi atomic interactions. The influence of the rubber shield surface density $x$ on the intensity $R_{\mathrm{f}}$ on the 89.9 and $77.1 \mathrm{keV}$ characteristic $\mathrm{Bi}$ lines is shown for the two rubber composites; those containing the different $\mathrm{Bi}$ concentrations M1 and G1 are presented in Fig. 3a.

Figure 3 a clearly shows that the saturation intensity of these two Bi lines is observed for a thickness of approximately $0.7-0.8 \mathrm{~g} / \mathrm{cm}^{2}$. Increasing the Bi concentration only slightly influences the $89.9 \mathrm{keV}$ line intensity, whereas the $77.1 \mathrm{keV}$ line intensity is affected to a higher extent. This line $(77.1 \mathrm{keV})$ may cause undesirable effects on the quality of the CT scans, thus its intensity should be reduced not only by increasing the thickness of the shields but also by adding another metal capable of absorbing these photons in the range of $72-79 \mathrm{keV}$. Tungsten, for example, exhibits a high attenuation coefficient in the range of 69-80 keV [21, 22]. The addition of tungsten-for which the $\mathrm{K}$ absorption edge ( $69.5 \mathrm{keV})$ [25] is just below the $\mathrm{Bi}$ emission energies-is especially beneficial due to the corresponding energy values for $\mathrm{Bi}$ emission and $\mathrm{W}$ absorption. However, when these two metals are the only additives, the undesirable effects of the tungsten emissions can be observed in the 58-60 keV energy range, which is still important to the CT protocols. As previously mentioned, the intensities can be further reduced by the addition of another metallic compound with a lower atomic number, $Z$, for example, Gd. In such systems, the reduction in photon emission intensity for all spectral energies from 58 to $90 \mathrm{keV}$ is clearly observed and presented in Fig. 2. In the presence of the $\mathrm{Gd}$, photons emitted from the $\mathrm{W}$ atoms are absorbed more efficiently by shields that have a total thickness greater than $0.5 \mathrm{~g} / \mathrm{cm}^{2}$. The emission saturation maxima of these $\mathrm{W}$ photons are shifted toward lower thickness values comparing with those for Bi (Fig. 3b).

The question remains as to the measurable effects of the addition of heavy metals in the order of $\mathrm{Bi}, \mathrm{W}, \mathrm{Gd}$ and $\mathrm{Sb}$, and how these additives and their concentrations influence the dose absorbed in the tissue. A suitable parameter for describing the protective shield should provide information regarding the ability of this material to reduce the dose. In a simple approach, the dose rate can be calculated as the sum of the products of the radiation flux $\left(I\right.$, in $\left.1 / \mathrm{cm}^{2} \mathrm{~s}\right)$, the mass attenuation coefficient for the material being irradiated (tissue, $\mu_{\mathrm{TS}}$ in $\mathrm{cm}^{2} / \mathrm{g}$ ) and the energy of the absorbed photon(s) ( $E$ in $\mathrm{keV}$ ) with $k$ as an unit correction factor. This dependence can be summarised by Eq. 5 as follows:

$D=k \sum_{i} I_{i} \mu_{\mathrm{TS}} E_{i}$

Using the above formula, a dose rate can be estimated for cases both with and without application of an elastomeric shielding material.

The dose reduction factor (DRF) coefficient can be used to assess the shielding properties of the elastomeric composites. The DRF coefficient can be defined simply as a ratio of the dose absorbed after the application of an elastomeric shield $(D)$ to that without the application of a
Table 4 Calculated dose reduction factors (DRF) for examined composites a $\mathrm{X}$-ray fluorescence radiation of $\mathrm{Bi}, \mathrm{W}$ and $\mathrm{Gd}$ involved

b Only for 122.1 and $136.5 \mathrm{keV}$ $\mathrm{Co}^{57}$ photons

\begin{tabular}{llllllll}
\hline Composite & Additive(s) & $\begin{array}{l}d\left(\mathrm{~g} / \mathrm{cm}^{2}\right) \\
(1 \text { layer })\end{array}$ & $\mathrm{DRF}^{\mathrm{a}}$ & $\mathrm{DRF}^{\mathrm{b}}$ & $\begin{array}{l}d\left(\mathrm{~g} / \mathrm{cm}^{2}\right) \\
(2 \text { layers })\end{array}$ & $\mathrm{DRF}^{\mathrm{a}}$ & $\mathrm{DRF}^{\mathrm{b}}$ \\
\hline $\mathrm{M} 1$ & $\mathrm{Bi}$ & 0.195 & 0.79 & 0.78 & 0.391 & 0.61 & 0.60 \\
$\mathrm{M} 2$ & $\mathrm{Bi}+\mathrm{W}$ & 0.244 & 0.72 & 0.70 & 0.488 & 0.50 & 0.49 \\
$\mathrm{M} 3$ & $\mathrm{Bi}+\mathrm{W}+\mathrm{Gd}$ & 0.230 & 0.73 & 0.72 & 0.460 & 0.51 & 0.50 \\
$\mathrm{M} 4$ & $\mathrm{Bi}+\mathrm{W}+\mathrm{Gd}+\mathrm{Sb}$ & 0.236 & 0.73 & 0.72 & 0.472 & 0.52 & 0.51 \\
$\mathrm{G} 1$ & $\mathrm{Bi}$ & 0.134 & 0.89 & 0.88 & 0.267 & 0.78 & 0.77 \\
$\mathrm{G} 2$ & $\mathrm{Bi}+\mathrm{W}$ & 0.178 & 0.82 & 0.81 & 0.355 & 0.67 & 0.66 \\
$\mathrm{G} 3$ & $\mathrm{Bi}+\mathrm{W}+\mathrm{Gd}$ & 0.176 & 0.82 & 0.81 & 0.352 & 0.66 & 0.65 \\
$\mathrm{G} 4$ & $\mathrm{Bi}+\mathrm{W}+\mathrm{Gd}+\mathrm{Sb}$ & 0.174 & 0.80 & 0.80 & 0.349 & 0.65 & 0.64 \\
$\mathrm{EP}$ & $\mathrm{Bi}+\mathrm{W}+\mathrm{Gd}$ & 0.162 & 0.79 & 0.78 & 0.322 & 0.62 & 0.61 \\
$\mathrm{Z}$ & $\mathrm{Bi}$ & 0.172 & 0.78 & 0.77 & 0.344 & 0.61 & 0.60 \\
\hline
\end{tabular}


shielding material $\left(D_{\mathrm{o}}\right)$. The DRF factor can be expressed as follows:

$\mathrm{DRF}=\frac{D}{D_{\mathrm{o}}}=\frac{\sum_{i} I_{i} \mu_{\mathrm{TS}} E_{i}}{\sum_{i} I_{i}^{o} \mu_{\mathrm{TS}} E_{i}}$

The values of the DRF coefficients for the investigated composites, calculated according to Eq. 6, are listed in Table 4. The DRF coefficients for $\mathrm{Co}-57$ radiation are presented with the DRF values calculated including both Co-57 and X-ray fluorescence radiation for comparison. As shown, these values are similar regardless of the method of calculation, with or without considering any X-ray fluoresce radiation induced within the shield material. Differences in the dose reduction factor values are at most $1-2 \%$ for a $1 \mathrm{~mm}$ thick layer. Nevertheless, our results clearly indicate that X-ray fluorescence should be taken into account when estimating the total dose reduction for a particular shielding material containing heavy metal additives.

\section{Conclusions}

Common methods used for determining the shielding properties of materials used in CT examinations require the application of devices such as TLD dosimeters or ionisation chambers and body phantoms to simulate the conditions of human-body CT examinations. Our method is based solely on simple X-ray spectrometric measurements including the fluorescence radiation generated in the shields. Results of our investigations revealed, that fluorescence radiation from the metal additives present in the elastomeric shields have slight contribution to the dose reduction during CT examination. However, the fluorescence radiation in the range of $58-90 \mathrm{keV}$ emitted from two frequently used metal additives, $\mathrm{Bi}$ and $\mathrm{W}$, can influence the quality of CT scans. Therefore, the addition of the third metal component, Gd, can substantially shift this radiation to the range of $40 \mathrm{keV}$, which is less critical for this diagnostic procedure. Another option involves the addition of a fourth metal additive, $\mathrm{Sb}$, to the elastomer shield to decrease the dose. Among the shielding materials examined, the elastomers most able to reduce the radiation dose are those that contain at least three heavy metal additives in concentrations that gradually decrease in the order of Bi, W, Gd and Sb (composites M2-M4).

Acknowledgments The authors are grateful to Polish National Centre for Research and Development for fundings; Grant No: NR050087-10/2010.

Open Access This article is distributed under the terms of the Creative Commons Attribution License which permits any use, distribution, and reproduction in any medium, provided the original author(s) and the source are credited.

\section{References}

1. UN Publication (2011) United Nations Scientific Committee on the effects of atomic radiation UNSCEAR 2008 report to the general assembly, with scientific annexes

2. Hart D, Wall BF, Hiller MC, Shrimpton PC (2010) Frequency and collective dose for medical and dental $\mathrm{X}$-ray examinations in the UK, 2008. Br J Radiol 75:1-4

3. Berrington de González A, Mahesh M, Kim K et al (2009) Projected cancer risks from computed tomographic scans performed in the united states in 2007. Arch Intern Med 169:2071-2077

4. Frush DP (2004) Review of radiation issues for computed tomography. Semin Ultrasound CT MR 25:17-24

5. Brenner D, Elliston C, Hall E, Berdon W (2001) Estimated risks of radiation-induced fatal cancer from pediatric CT. AJR 176:289-296

6. Curtis JR (2010) Computed tomography shielding methods: a literature review. Radiol Technol 81:428-436

7. Harbron RW (2012) Cancer risks from low dose exposure to ionising radiation-is the linear no-threshold model still relevant? Radiography 18:28-33

8. Hendee WR, O'Connor MK (2012) Radiation risks of medical Imaging: separating fact from fantasy. Radiology 264:312-321

9. Adams MJ, Shore RE, Dozier A, Lipshultz SE, Schwartz RG, Constine LS et al (2010) Thyroid cancer risk 40+ years after irradiation for an enlarged thymus: an update of the Hempelmann cohort. Radiat Res 174:753-762

10. Pearce MS, Salotti JA, Little MP, McHugh K, Lee C, Kim KP et al (2012) Radiation exposure from CT scans in childhood and subsequent risk of leukaemia and brain tumours: a retrospective cohort study. Lancet 380:499-505

11. Dougeni E, Faulkner K, Panayiotakis G (2012) A review of patient dose and optimisation methods in adult and paediatric CT scanning. Eur J Radiol 81:e665-e683

12. Mukundan S Jr, Wang PI, Frush DP, Yoshizumi T, Marcus J, Kloeblen E et al (2007) MOSFET dosimetry for radiation dose assessment of bismuth shielding of the eye in children. AJR 188:1648-1650

13. Kim S, Yoshizumi TT, Frush DP, Anderson-Evans C, Toncheva G (2009) Dosimetric characterisation of bismuth shields in CT: measurements and Monte Carlo simulations. Radiat Prot Dosimetry 133(2):105-110

14. Kalra MK, Dang P, Singh S, Saini S, Shepard JA (2009) In-plane shielding for CT: effect of off-centering, automatic exposure control and shield-to-surface distance, Korean J. Radiology 10:156-163

15. The American Association of Physicists in Medicine (2012) Use of Bismuth Shielding for the Purpose of Dose Reduction in CT Scanning, Professional/Education/Science Policies, vol 4., p 26

16. Halliburton SS, Abbara S, Chen MY, Gentry R, Mahesh M, Raff GL et al (2011) Society of cardiovascular computed tomography, SCCT guidelines on radiation dose and dose-optimization strategies in cardiovascular CT. J Cardiovasc Comput Tomogr 5:198-224

17. McCollough CH, Wang J, Berland LL (2011) Bismuth shields for CT dose reduction: do they help or hurt? J Am Coll Radiol 8:878-879

18. McCollough CH, Wang J, Gould RG, Orton CG (2012) Point/ counterpoint. The use of bismuth breast shields for CT should be discouraged. Med Phys 39:2321-2324

19. Kusiak E, Zaborski M, Bem H, Baryn W (2010) Elastomery zawierające związki bizmutu chroniące przed promieniowaniem X. Przem Chem 89:454-456

20. Bem H, Wieczorkowski P, Budzanowski M (2002) Evaluation of technologically enhanced natural radiation near the coal-fired 
power plants in the Lodz region of Poland. J Environ Radioact 61:191-201

21. Hubbell JH (1982) Photon mass attenuation and energy-absorption coefficients from $1 \mathrm{keV}$ to $20 \mathrm{MeV}$. Int J Appl Radiat Isot 33:1269-1290

22. Berger MJ, Hubbell JH, Seltzer SM, Chang J, Coursey JS, Sukumar R, et al (2010) XCOM: Photon Cross Section Database (version 1.5)

23. Berger MJ, Coursey JS, Zucker MA, Chang J (2005) ESTAR, PSTAR, and ASTAR: Computer programs for calculating stopping-power and range tables for electrons, protons, and helium ions (version 1.2.3). Handbook of radioactivity analysis. National Institute of Standards and Technology, Gaithersburd

24. International Commission on Radiation Units and Measurements (1989) Tissue substitutes in radiation dosimetry and measurement. ICRU Report 44. Bethesda, Maryland: ICRU Publications

25. Zschornack GH (2007) Handbook of X-ray data. Springer, Berlin

26. Beckhoff B, Kanngiesser B, Langhoff N, Wedell R, Wolff $\mathrm{H}$ (2006) Handbook of practical x-ray fluorescence analysis. Wiley, New York

27. McParland BJ (2010) Nuclear Medicine Radiation Dosimetry: Advanced Theoretical Principles 